\title{
Cell-Free System for Assembly of Transcriptionally Repressed Chromatin from Drosophila Embryos
}

\author{
PETER B. BECKER † AND CARL WU* \\ Laboratory of Biochemistry, National Cancer Institute, Building 37, \\ Room 4C-09, Bethesda, Maryland 20892
}

Received 9 December 1991/Accepted 26 February 1992

\begin{abstract}
We describe a cell-free system, derived from preblastoderm Drosophila embryos, for the efficient assembly of cloned DNA into chromatin. The chromatin assembly system utilizes endogenous core histones and assembly factors and yields long arrays of regularly spaced nucleosomes with a repeat length of $180 \mathrm{bp}$. The assembly system is also capable of complementary-strand DNA synthesis accompanied by rapid nucleosome formation when the starting template is single-stranded circular DNA. Chromatin assembled with the preblastoderm embryo extract is naturally deficient in histone $\mathrm{H1}$, but exogenous $\mathrm{H1}$ can be incorporated during nucleosome assembly in vitro. Regular spacing of nucleosomes with or without histone $\mathrm{H1}$ is sufficient to maximally repress transcription from $h s p 70$ and fushi tarazu gene promoters. The Drosophila assembly system should be particularly useful for in vitro studies of chromatin assembly during DNA synthesis and for elucidating the action of transcription factors in the context of native chromatin.
\end{abstract}

Transcription in eukaryotes is generally associated with local changes of the regular chromatin structure and composition (see reference 14 for a review). While "active chromatin" as a technical term has been in existence for many years, the exact nature and determinants of these activated regions are largely unknown $(28,43)$. In general, sites of transcription appear to be less condensed and thus more accessible than the tightly packed bulk chromatin. Probing the accessibility of sequences with nucleases in isolated nuclei has yielded a wealth of information about the localization of regulatory sites, such as enhancers or promoters, and their potential or actual activity.

While the correlations between transcription and accompanying chromatin features are well established, it has only recently been appreciated that structural components of chromatin can be used to regulate gene activity in a highly specific manner $(16,17,42,45)$. It has been shown that nucleosomes that are positioned in vivo with regard to the underlying DNA sequence can influence transcription and replication by modulating the accessibility of regulatory sites for the binding of protein factors in vivo. Conversely, DNA-binding proteins have been described that activate or repress transcription by influencing the position of nucleosomes in the vicinity of important regulatory sequences $(10$, $19,31,37,46)$. To elucidate these phenomena at the molecular level, an in vitro reconstruction of the mutual interdependence of transcriptional regulators and structural components of chromatin under physiological conditions is necessary.

We are interested in general aspects of transcriptional regulation by RNA polymerase II in the context of chromatin, using the fruit fly Drosophila melanogaster as a model system. A priori, Drosophila embryos should be an excellent source of factors required for nucleosome assembly: during the initial stages of embryonic development, the fly genome is replicated and packaged into chromatin once every $9 \mathrm{~min}$

\footnotetext{
* Corresponding author.

† Present address: Gene Expression Program, European Molecular Biology Laboratory, Meyerhofstrasse 1, D-6900 Heidelberg, Germany.
}

by using a maternal pool of histones and assembly factors (11). A cell-free system for nucleosome assembly derived from early Drosophila embryos has been reported previously (25). However, this procedure has not been adopted by workers in the field, and our attempts to create an efficient assembly extract according to the published procedure were not successful. Here we report the development of a stable and very efficient cell-free system for nucleosome assembly using Drosophila embryos. The system is also able to carry out a DNA synthesis reaction that mimics lagging-strand replication. We find that assembly of nucleosomes on $h s p 70$ and fushi tarazu DNA templates is sufficient to maximally repress transcription in vitro, with or without the concomitant assembly of histone H1.

\section{MATERIALS AND METHODS}

Extract preparation. Drosophila embryos 0 to $100 \mathrm{~min}$ after egg laying were rinsed in water and allowed to settle into embryo wash buffer $(0.7 \% \mathrm{NaCl}, 0.05 \%$ Triton X-100) on ice to arrest further development. After four to five successive collections, the pooled harvest was dechorionated. The wash buffer was decanted and replaced with wash buffer at room temperature, and the volume was adjusted to $200 \mathrm{ml}$. After the addition of $200 \mathrm{ml}$ of Chlorox bleach, the embryos were stirred vigorously for $90 \mathrm{~s}$, poured back into the collection sieve, and rinsed extensively with tap water. They were then allowed to settle in 1 liter of wash buffer for about $2 \mathrm{~min}$, after which the supernatant (containing the chorions) was aspirated off. Four more settlings were performed: one in wash buffer, two in $0.7 \% \mathrm{NaCl}$, and one in extract buffer [10 mM $N$-2-hydroxyethylpiperazine- $N^{\prime}-2$ ethanesulfonic acid (HEPES, pH 7.6), $10 \mathrm{mM} \mathrm{KCl}, 1.5 \mathrm{mM}$ $\mathrm{MgCl}_{2}, 0.5 \mathrm{mM}$ ethylene glycol-bis( $\beta$-aminoethyl ether)$N, N, N^{\prime}, N^{\prime}$-tetraacetic acid (EGTA), $10 \%$ glycerol, $10 \mathrm{mM}$ $\beta$-glycerophosphate; $1 \mathrm{mM}$ dithiothreitol and $0.2 \mathrm{mM}$ phenylmethylsulfonyl fluoride, added freshly) at $4^{\circ} \mathrm{C}$. The embryos in extract buffer were settled in a $60-\mathrm{ml}$ glass homogenizer on ice for about $15 \mathrm{~min}$, and the volume of the packed embryos was estimated ( $\sim 10$ to $15 \mathrm{ml})$. The supernatant was aspirated, and the embryos were homogenized by six com- 
plete strokes with a Teflon pestle connected to a drill press. All further manipulations were carried out at $4^{\circ} \mathrm{C}$. The homogenate was supplemented with additional $5 \mathrm{mM} \mathrm{MgCl} 2$ from a $1 \mathrm{M} \mathrm{MgCl}_{2}$ stock solution and quickly mixed (final $\mathrm{MgCl}_{2}$ concentration, $6.5 \mathrm{mM}$ ). When nucleosome assembly was assayed at low $\mathrm{MgCl}_{2}$ concentrations, no $\mathrm{MgCl}_{2}$ was added to the embryo homogenate (final $\mathrm{MgCl}_{2}$ concentration, $1.5 \mathrm{mM}$ ). Nuclei were pelleted by centrifugation for 5 min at 5,000 rpm in a JA14 rotor (Beckman). The supernatant was clarified by centrifugation for $2 \mathrm{~h}$ at $40,000 \mathrm{rpm}$ $(150,000 \times g)$ in an SW 50.1 rotor (Beckman) and collected with a syringe by puncturing the tubes just above the solid pellet, avoiding the floating layer of lipid. Aliquots ( 300 to $500 \mu \mathrm{l}$ ) were frozen in liquid nitrogen. Protein concentrations were determined with the Bradford assay, using bovine serum albumin as the standard; they were usually between 20 and $30 \mathrm{mg} / \mathrm{ml}$.

At the last settling step in the extract buffer, not all embryos settle because of changes in osmolarity. In addition, variable degrees of settling will result in corresponding variable final extract protein concentrations. To standardize the yields of the extract preparation, an alternative procedure was employed. After the settling in $0.7 \% \mathrm{NaCl}$, the embryo suspension was poured onto a filter paper on a Büchner funnel, filtered under vacuum, and washed twice with $100 \mathrm{ml}$ of extract buffer. The damp embryos were resuspended in $1 \mathrm{ml}$ of cold extract buffer per $\mathrm{g}$ of embryos. Homogenization and centrifugation were performed as described above. When assayed by micrococcal nuclease digestion, this procedure yielded extracts which assembled chromatin with an efficiency identical to that of the one described above. It did, however, contain protein aggregates (which did not disperse in $0.05 \%$ Nonidet P-40) that cosedimented with the minichromosomes during sucrose gradient purification and masked the analysis of histone assembly. Extracts of this kind were therefore not used routinely.

Assembly reaction. In a standard assembly reaction, $1.5 \mu \mathrm{g}$ of plasmid DNA was incubated at $26^{\circ} \mathrm{C}$ with $3 \mathrm{mg}$ of embryo extract protein and the following reagents (which were added from a $10 \times$ premix): $30 \mathrm{mM}$ creatine phosphate, $3 \mathrm{mM}$ $\mathrm{MgCl}_{2}, 3 \mathrm{mM}$ ATP ( $\mathrm{pH}$ 8), $0.1 \mu \mathrm{g}$ of creatine phosphokinase (type 1; Sigma) per $\mathrm{ml}$, and $1 \mathrm{mM}$ dithiothreitol. The volume was adjusted to $200 \mu \mathrm{l}$ with extract buffer. The final conductivity in the assembly reactions is equivalent to $65 \mathrm{mM} \mathrm{KCl}$. The protein concentration for optimal assembly was determined for every extract, using the micrococcal nuclease assay. Unless stated otherwise, the $\mathrm{MgCl}_{2}$ concentration in the assembly was adjusted to 6.5 to $7 \mathrm{mM}$, taking into account the $\mathrm{MgCl}_{2}$ that had been added during the extract preparation. Reactions with exogenous histone $\mathrm{H} 1$ were mixed with the histone prior to the addition of DNA.

Supercoiling analysis. At various times during the reaction, $40 \mu \mathrm{l}$ of assembly mixture was removed and $10 \mu \mathrm{l}$ of $5 \times$ stop mix (2.5\% Sarkosyl, $100 \mathrm{mM}$ EDTA) and $1 \mu \mathrm{l}$ of DNase-free RNase (Boehringer Mannheim) were added; the mixture was then incubated for $15 \mathrm{~min}$ at $37^{\circ} \mathrm{C}$. Then $6.5 \mu \mathrm{l}$ each of $2 \%$ sodium dodecyl sulfate (SDS) and $10-\mathrm{mg} / \mathrm{ml}$ proteinase $\mathrm{K}$ were added and again incubated for $30 \mathrm{~min}$ at $37^{\circ} \mathrm{C}$. The DNA was precipitated with 2 volumes of ethanol after the addition of $1 \mu \mathrm{l}$ of glycogen $(10 \mu \mathrm{g})$ and $45 \mu \mathrm{l}$ of $7.5 \mathrm{M}$ ammonium acetate. After centrifugation, the DNA was washed with $80 \%$ ethanol, dried under vacuum, and finally dissolved in $8 \mu \mathrm{l}$ of TE $(10 \mathrm{mM}$ Tris $\mathrm{HCl}[\mathrm{pH} 7.5], 1 \mathrm{mM}$ EDTA). DNA was electrophoresed on a $1.2 \%$ agarose gel with Tris-glycine buffer (lacking ethidium bromide) for $15 \mathrm{~h}$ at $20 \mathrm{~V}$.
Micrococcal nuclease analysis. To a standard assembly reaction, $6 \mu \mathrm{l}$ of $0.1 \mathrm{M} \mathrm{CaCl}_{2}$ was added and quickly mixed. A $40-\mu l$ portion of the mixture was removed and treated the same as for supercoiling analysis. To the remaining reaction, $5 \mu \mathrm{l}$ of micrococcal nuclease (Boehringer Mannheim; 50 $\mathrm{U} / \mu \mathrm{l}$ in extract buffer) was added. After $0.5,2$, and $8 \mathrm{~min}$ at room temperature, $40 \mu \mathrm{l}$ was again removed and the digestion was terminated. An RNase treatment for up to $1 \mathrm{~h}$ was followed by overnight proteinase $\mathrm{K}$ digestion. Gel electrophoresis of the micrococcal nuclease digestion products was as described in detail by Shimamura et al. (35). Micrococcal nuclease analysis of Drosophila embryo chromatin was performed as described by Wu et al. (50).

DNA templates. In the experiments presented here, the plasmid phsp $70 \Delta 185(3,443 \mathrm{bp})$, which contains $h s p 70$ (locus $87 \mathrm{~A})$ gene sequences between the $X$ hoI site at -185 and the $A c c$ I site at $+300(+1$ is the transcriptional start), was used. The XhoI-AccI fragment was filled in with T4 polymerase and cloned into the HincII site of pBluescript SK M13+ (Stratagene). Single-stranded DNA was purified from phage particles after superinfection of a bacterial culture containing the plasmid with helper phage VCSM13 (Stratagene) according to standard procedures. A variant of phsp70 185 ( $h s p 70$ minigene) was constructed by deleting an AluI fragment $(+41$ to +71$)$ as described previously (6). The plasmid carrying the fushi tarazu promoter $(-950$ to +151$)$ was as described previously (6).

Replication assay. Conditions for the replication assay were similar to those for standard nucleosome assembly reactions, except that $750 \mathrm{ng}$ of single-stranded DNA instead of double-stranded plasmid DNA was used. For "uniform labeling," $1 \mu \mathrm{l}$ of $\left[\alpha-{ }^{32} \mathrm{P}\right] \mathrm{dCTP}$ at 2,000 to $3,000 \mathrm{Ci} / \mathrm{mmol}$ (NEN) was added. For site-specific labeling, the singlestranded DNA was first annealed with a fivefold molar excess of a ${ }^{32} \mathrm{P}$-end-labeled primer ( $h s p 70$ nucleotides -185 to -153 ) in $20 \mu \mathrm{l}$ of $100 \mathrm{mM} \mathrm{NaCl}-5 \mathrm{mM} \mathrm{MgCl}_{2}$. The mixture was incubated for $5 \mathrm{~min}$ at $75^{\circ} \mathrm{C}, 10 \mathrm{~min}$ at $37^{\circ} \mathrm{C}$, and $5 \mathrm{~min}$ at $26^{\circ} \mathrm{C}$; the extract and assembly components (without radiolabeled dCTP) were then added.

Histone purifications. Core histones as standards for gel electrophoresis were purified from the chromatin of 0 - to 20-h-old embryos according to the method of Simon and Felsenfeld (36). They were identified by their migration behavior on SDS gels (44). H1 was purified from nuclei of 0 to 12 -h embryos by the procedure of Croston et al. (8). The peak fraction of the phenyl-Sepharose column was concentrated four- to fivefold by vacuum dialysis in a mini-collodion bag (Schleicher \& Schuell).

Plasmid chromatin purification. A total of $1.5 \mu \mathrm{g}$ of singlestranded DNA or $3 \mu \mathrm{g}$ of double-stranded plasmid DNA was assembled for $6 \mathrm{~h}$ under standard conditions. The synthesis of the complementary strand was followed by the introduction of $3 \mu \mathrm{l}$ of $\left[\alpha-{ }^{32} \mathrm{P}\right] \mathrm{dCTP}$ to the samples containing single-stranded DNA. Purification of chromatin was achieved by centrifugation through a 15 to $30 \%$ sucrose gradient followed by pelleting through a $30 \%$ sucrose cushion exactly as described previously (35). The chromatincontaining fractions were identified by the incorporation of radioactivity. Silver staining of the histone gels was done as described by Wray et al. (49).

Transcription of assembled templates. Drosophila embryo transcription extracts were prepared and coupled assemblytranscription reactions were processed as described previously (6), with the following modifications. The chromatin assembly reaction was scaled down to $50 \mu \mathrm{l}$ in proportion to the input amount of DNA template ( $180 \mathrm{ng}$ each of the $h s p 70$ 


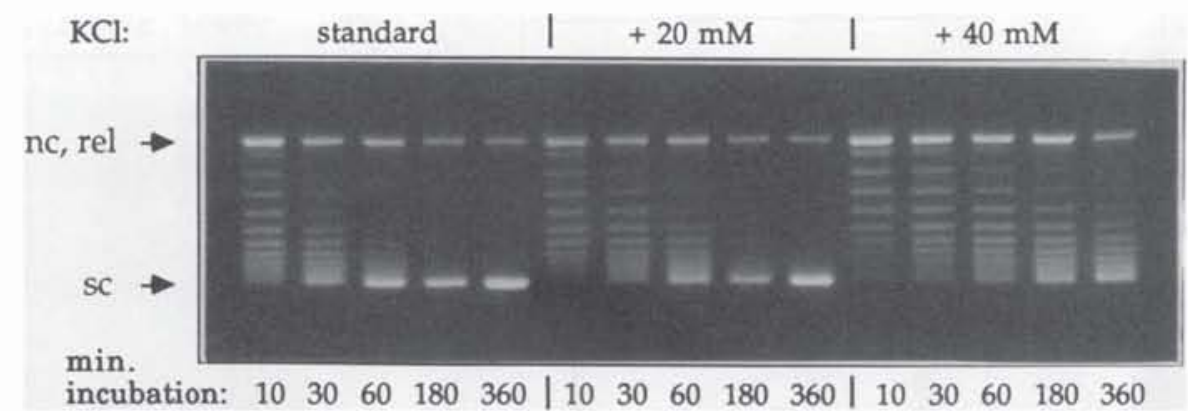

FIG. 1. Chromatin assembly analyzed by DNA supercoiling analysis. Supercoiled plasmid $(1.5 \mu \mathrm{g})$ was incubated under standard conditions with $2 \mathrm{mg}$ of extract protein in the presence of $6.5 \mathrm{mM} \mathrm{MgCl}$ and the indicated concentrations of $\mathrm{KCl}$. At various times, aliquots were removed from the reaction. DNA was deproteinized, electrophoresed on a $1.2 \%$ agarose gel in Tris-glycine buffer, and stained with ethidium bromide. Comparison with DNA prepared from a reaction point at time zero showed no significant loss of input DNA during the reaction (data not shown). The positions in the gel of nicked (nc), relaxed closed (rel), and supercoiled (sc) plasmids are marked by arrows.

and $f t z$ plasmids). To $5 \mu l$ of the assembled chromatin reaction was added $2 \mu \mathrm{l}$ of $0.5-\mu \mathrm{g} / \mu \mathrm{l}$ pUC vector DNA and $18 \mathrm{ng}$ of $h s p 70$ minigene in $9 \mu \mathrm{l}$ of HEMG $(25 \mathrm{mM}$ HEPES [pH 7.6], $0.1 \mathrm{mM}$ EDTA, $12.5 \mathrm{mM} \mathrm{MgCl} 2,10 \%$ glycerol). Four microliters of unshocked embryo transcription extract (6) and $5 \mu \mathrm{l}$ of the following components (final concentrations) were added: $500 \mu \mathrm{M}$ (each) ATP, GTP, CTP, and UTP; $4 \mathrm{mM}$ creatine phosphate; 10 ng of creatine phosphokinase; $5 \mathrm{U}$ of RNasin; $4 \mathrm{mM}$ dithiothreitol. The $25-\mu \mathrm{l}$ reaction mixture was then incubated for $20 \mathrm{~min}$ at $26^{\circ} \mathrm{C}$. RNA products were purified and analyzed by primer extension (6). Quantitation of the radioactivity was performed on dried polyacrylamide gel slices by liquid scintillation counting.

\section{RESULTS}

In vitro assembly of nucleosomes with regular spacing on plasmid DNA. In order to minimize the dilution of cytoplasmic components and to reduce the extraction of nuclear proteins, the procedure for preparing the Drosophila nucleosome assembly extract involves the homogenization of staged, preblastoderm embryos in a small volume of low-salt extraction buffer. Nuclei are pelleted by centrifugation, and the cytosolic supernatant is clarified by centrifugation at $150,000 \times g(\mathrm{~S}-150)$. This crude S-150 extract contains the major components necessary to assemble nucleosomes on microgram quantities of plasmid DNA. When supplemented with ATP, $\mathrm{MgCl}_{2}$, and an energy-regenerating system (3, 35 ), the assembly of regularly spaced nucleosomes is achieved.

The ability of the Drosophila extract to assemble nucleosomes was initially assayed by DNA supercoiling analysis $(13,23,29)$. The winding of DNA around a nucleosomal core introduces about one positive superhelical turn in the DNA (13), which is rapidly relaxed by topoisomerase I activity, which is abundant in cell extracts. Deproteinization of the reconstituted plasmid chromatin results in the acquisition of one negative superhelical turn for each nucleosome assembled (21). Figure 1 shows the time course of plasmid supercoiling performed with Drosophila embryo extracts in the presence of increasing concentrations of $\mathrm{KCl}$. Upon incubation with the S-150 extract $(10 \mathrm{~min})$, the negatively supercoiled plasmid was initially relaxed by topoisomerase I activity. Further incubation resulted in the reintroduction of DNA supercoils, suggesting the assembly of nucleosomal or nucleosomelike structures. DNA supercoiling was found to be inhibited by the presence of $\mathrm{KCl}$ concentrations greater than that already present in a standard reaction (the standard salt concentration is equivalent in conductivity to $65 \mathrm{mM}$ $\mathrm{KCl}$ ). Since the supercoiling assay was performed with a crude extract, it is difficult to ascribe the inhibitory effect of increased $\mathrm{KCl}$ to a specific component of the reaction. The effect of $\mathrm{KCl}$ concentrations lower than $65 \mathrm{mM}$ was not analyzed, as the assay was constrained by the salt contribution of the extract.

To assess whether the supercoiling of the plasmid was due to the assembly of nucleosomes, we subjected the assembled plasmid to digestion with micrococcal nuclease. Micrococcal nuclease cleaves chromatin in the linker DNA between the nucleosomes (27). A limit digest of chromatin typically creates DNA fragments of the size protected by a nucleosome core (146 nucleotides), while partial digests result in a ladder of fragments corresponding to oligonucleosome-sized DNAs. As shown in Fig. 2A, digestion of the assembled chromatin resulted in extremely well-resolved mono- and oligonucleosome-sized DNA fragments. A densitometer tracing revealed 19 distinct bands (Fig. 2B), suggesting the assembly of a maximum of 19 nucleosomes on some of the plasmid templates. On these templates, the average nucleosomal repeat length was calculated to be 181 bp $(3,443$ $\mathrm{bp} / 19)$. Measurement of the sizes of oligonucleosomal fragments also indicated the spacing of nucleosomes at $\sim 180$-bp intervals. We have made over 12 extract preparations by this procedure with similar results and hence have adopted this as the standard protocol. The resolution of the oligonucleosomal DNA bands over the background smear was less apparent when the levels of $\mathrm{MgCl}_{2}$ were decreased below 6.5 $\mathrm{mM}$ (Fig. 2C). For reasons which are unclear, extracts that were prepared by adjusting the embryo homogenate to 6.5 $\mathrm{mM} \mathrm{MgCl} 2$ prior to (Fig. 2A) rather than after (Fig. 2C) the $\mathrm{S}-150$ centrifugation were superior in their potential to create extended nucleosomal arrays.

DNA synthesis and nucleosome assembly. In vivo nucleosome assembly occurs naturally on newly replicated DNA. To test for the presence of similar activities in our extracts, we substituted the plasmid DNA with single-stranded circular DNA and added $\left[\alpha-{ }^{32} \mathrm{P}\right] \mathrm{dCTP}$ as a precursor for DNA synthesis. Upon incubation with the extract, the complementary strand was synthesized and the bulk of the labeled material was recovered in the form of supercoiled DNA (Fig. $3 A)$. The assembly extract apparently contains DNA primase, polymerase(s), accessory factors, RNase $\mathrm{H}$, and DNA ligase activities necessary to perform lagging-strand DNA 

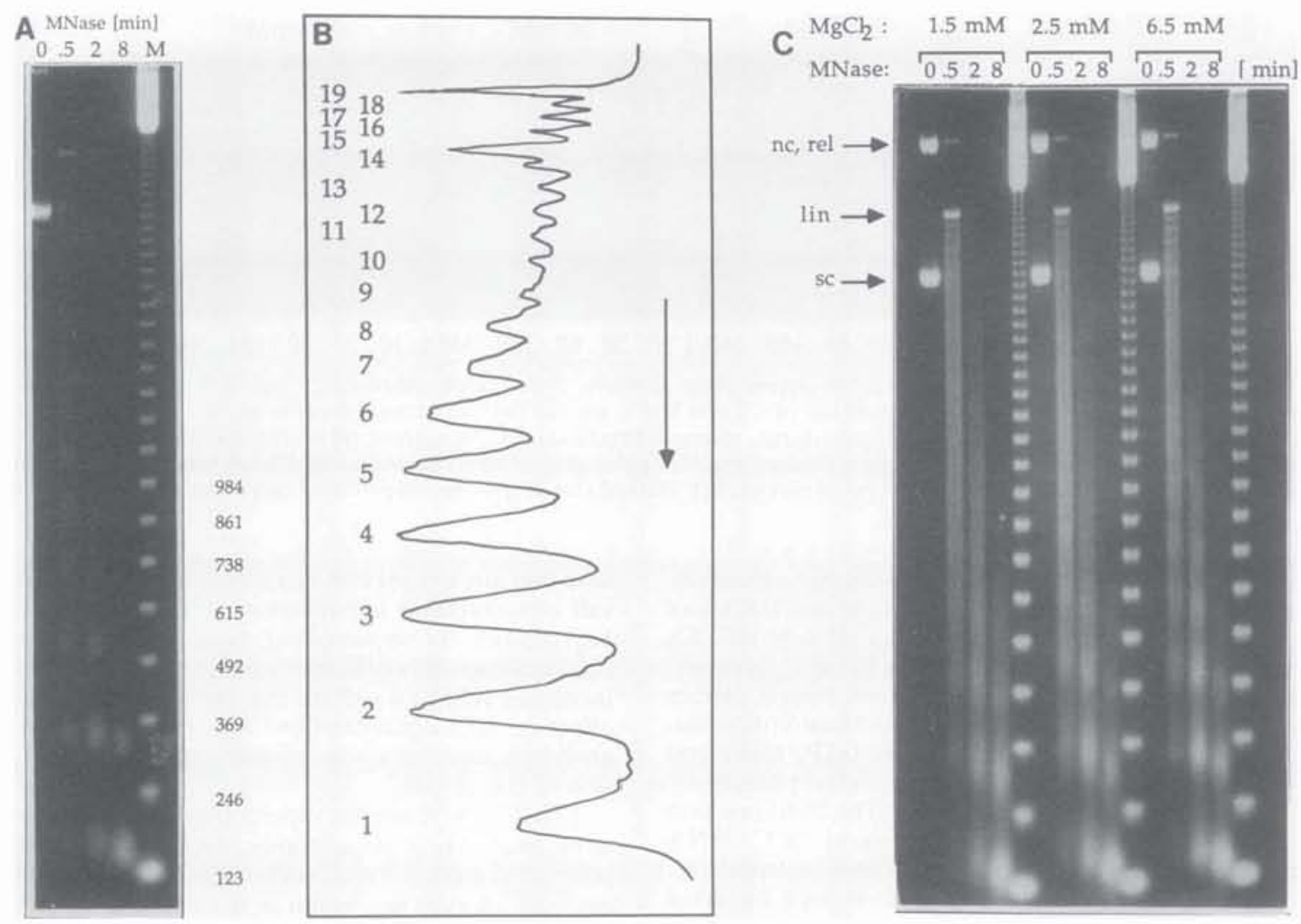

FIG. 2. Micrococcal nuclease analysis of reconstituted chromatin. (A) Chromatin assembled for $6 \mathrm{~h}$ under standard conditions was digested with micrococcal nuclease for the indicated times. The final $\mathrm{MgCl}_{2}$ concentration during the assembly reaction was $7 \mathrm{mM}$. Purified DNA fragments were resolved on $1.5 \%$ agarose gels and stained with ethidium bromide as described by Shimamura et al. (35). Lane M shows size markers consisting of 123-bp multimers (Bethesda Research Laboratories). (B) Densitometer tracing of the 0.5-min micrococcal nuclease digest shown in panel $\mathrm{A}$. The arrow indicates the direction of electrophoresis. (C) Assembly reactions containing the indicated concentrations of $\mathrm{MgCl}_{2}$ were incubated at $26^{\circ} \mathrm{C}$ for $6 \mathrm{~h}$. The reconstituted chromatin was digested with micrococcal nuclease for the indicated times. The positions in the gel of nicked (nc), relaxed closed (rel), linear (lin), and supercoiled (sc) plasmids are marked by arrows.

synthesis. The level of DNA synthesis was found to be stimulated by the presence of $\mathrm{MgCl}_{2}$ up to $6.5 \mathrm{mM}$.

To confirm that the supercoils in the newly synthesized DNA originate from the assembly of nucleosomes, micrococcal nuclease digestion assays were performed. First, DNA synthesis was traced by the incorporation of radiolabeled dCTP as described above, in a reaction that relied on endogenous primers in the assembly extract. This uniform labeling (Fig. 3B, right panel) displayed the overall chromatin assembly on the plasmid. Alternatively, a specific ${ }^{32} \mathrm{P}$ end-labeled primer was annealed to the single-stranded template before the addition of the extract. In this reaction, the labeled dCTP was omitted, and the micrococcal nuclease analysis therefore reflects chromatin assembly around the site where the primer annealed (Fig. 3B, left panel). In both reactions with single-stranded templates, assembly of regularly spaced nucleosomes over a significant fraction of the templates was already evident by $30 \mathrm{~min}$ of assembly, as gauged by the emergence of the ladder of oligonucleosomesized DNA fragments upon micrococcal nuclease cleavage. An increase in the duration of chromatin assembly ( 60 and $120 \mathrm{~min}$ ) further enhanced the ladder of DNA fragments, indicating complete or near complete deposition of nucleosomes on the DNA template.

Histone content of in vitro assembled nucleosomes. The regular spacing of the micrococcal nuclease cleavage sites in reconstituted chromatin is indicative of the assembly of nucleosomes. To extend this finding, we determined the histone composition of the reconstituted nucleosomes. Fully assembled plasmid chromatin (with single- or doublestranded DNA as the starting material) was purified by sucrose gradient centrifugation (35). The plasmid chromatin proteins were analyzed by SDS-polyacrylamide gel electrophoresis (SDS-PAGE) and silver staining (Fig. 4). From the reactions that contained either single-stranded (lane 1) or double-stranded (lane 2) DNA, a full complement of core histones of roughly equal stoichiometry could be recovered, while a reaction that was processed in parallel but lacked DNA (lane 3) displayed cosedimenting nonhistone proteins that were not associated with chromatin. It should also be noted that histone $\mathrm{Hl}$ was absent from the reconstituted chromatin, as no band of the expected size $(\sim 35 \mathrm{kDa}$; see below) was observed. Preblastoderm Drosophila embryos have been previously reported to be deficient in histone $\mathrm{H} 1$ (9). We have also observed an apparent histone variant in reconstituted chromatin that migrates above the histone H2B band on the gel. This variant is absent or poorly represented among the late embryo histones; the late embryo histones include another apparent, minor histone variant which migrates below the histone $\mathrm{H} 2 \mathrm{~A}$ position. 


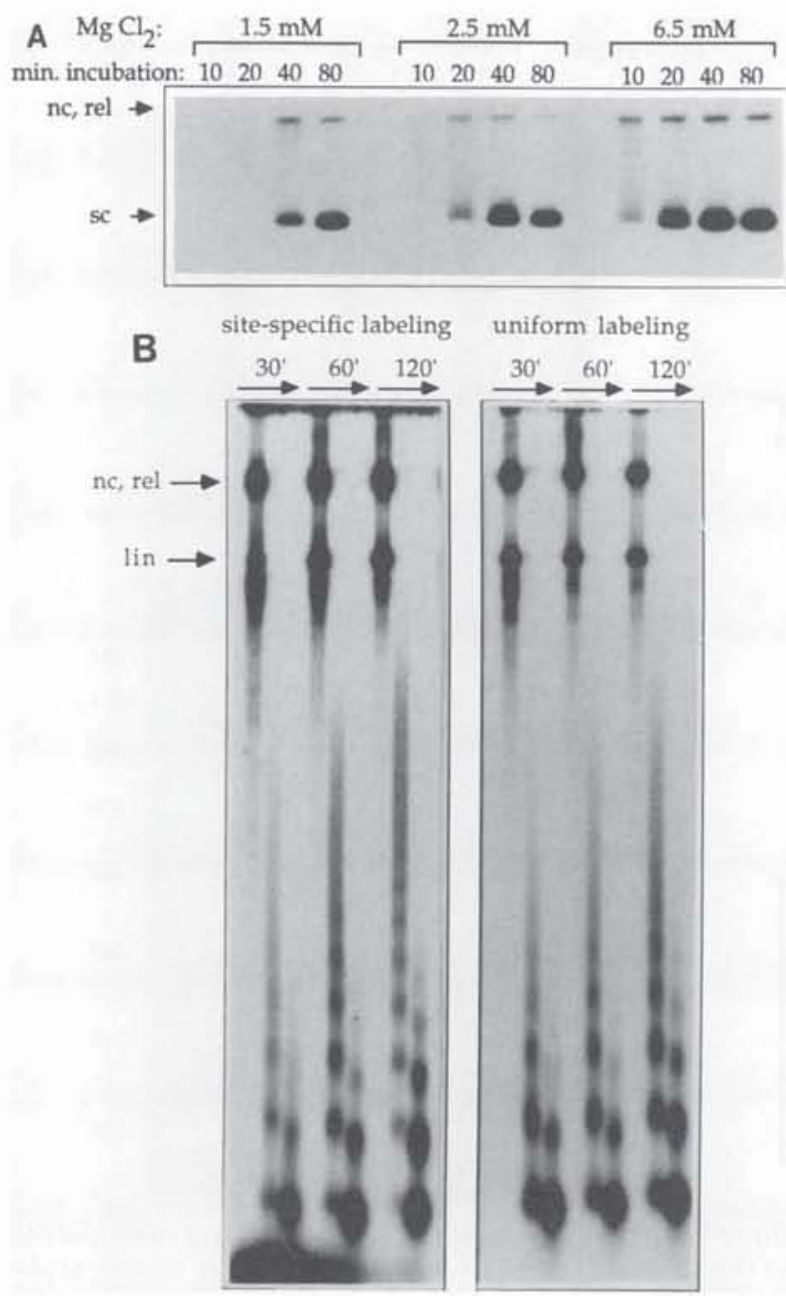

FIG. 3. (A) DNA synthesis in embryo extracts. Single-stranded, circular DNA was incubated in a standard assembly reaction in the presence of $\mathrm{MgCl}_{2}$ (concentrations as indicated) and $\left[\alpha-{ }^{32} \mathrm{P}\right] \mathrm{dCTP}$. Aliquots of the reaction were analyzed for DNA supercoiling by electrophoresis and autoradiography after the indicated periods of incubation. (B) Micrococcal nuclease analysis of newly synthesized plasmid DNA. Single-stranded DNA ( $660 \mathrm{ng}$ ) was incubated with 2.6 $\mathrm{mg}$ of embryo extract in a $150-\mu 1$ reaction mixture in the presence of $7 \mathrm{mM} \mathrm{MgCl}$. Left: $\alpha{ }^{-32} \mathrm{P}$-labeled oligonucleotide primer was annealed to the template prior to the addition of the extract. Radioactive dCTP was omitted from the reaction. Right: DNA synthesis relied on endogenous primers and was traced with radioactive dCTP. After incubation for the indicated times, the reactions were adjusted to $3 \mathrm{mM} \mathrm{CaCl}$ and digested with $190 \mathrm{U}$ of micrococcal nuclease (Boehringer Mannheim) for 0, 2, and 8 min (arrows indicate increasing digestion). DNA was analyzed by gel electrophoresis and autoradiography. The gel on the left was exposed 18 times longer than the gel on the right. The positions in the gel of nicked (nc), relaxed closed (rel), and linear (lin) plasmids are marked by arrows.

Incorporation of exogenous $\mathrm{H1}$ into reconstituted chromatin. Histone $\mathrm{H} 1$ has been suggested to play an important role in organizing chromatin and, in particular, to contribute to the inactive state of a gene $(8,24,34,46,51)$. Since chromatin reconstituted with the early embryo extract was deficient in $\mathrm{H} 1$, we have determined whether exogenous purified $\mathrm{Hl}$ could be incorporated into the chromatin.

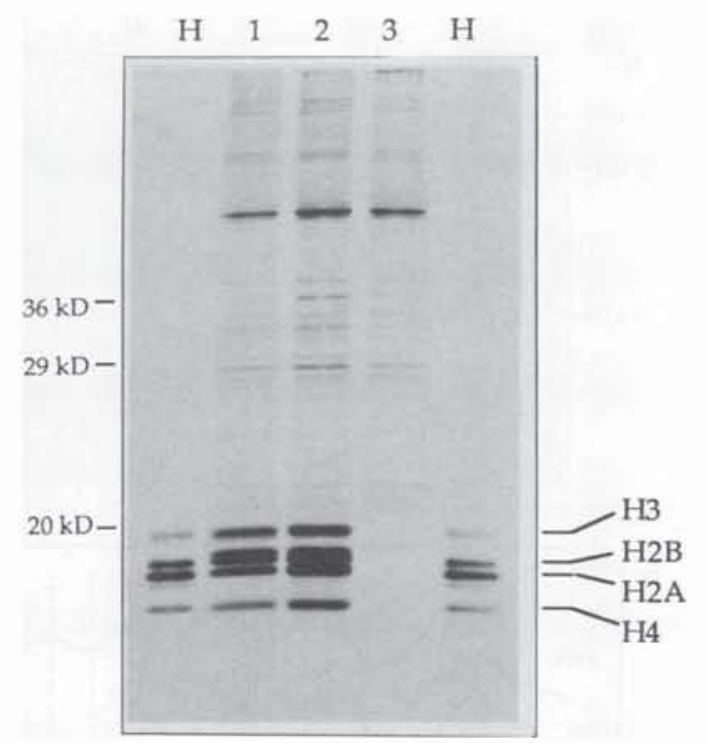

FIG. 4. Histone composition of reconstituted chromatin. Proteins that cosedimented with assembled plasmids on a sucrose gradient were separated by SDS-PAGE and stained with silver. Nucleosome assembly reactions contained either single-stranded DNA (lane 1), double-stranded DNA (lane 2), or no DNA (lane 3) as the starting material. The positions of protein size standards are indicated to the left. Lanes $\mathrm{H}$ : Marker core histones from chromatin of 0 - to 20 -h embryos.

H1 was purified from 0- to 12-h Drosophila embryos to near homogeneity (Fig. 5A, lane 2) and was introduced into the assembly extract prior to the addition of the DNA. As shown in Fig. 5A, incorporation of exogenous $\mathrm{H1}$ is evident by SDS-PAGE analysis of the histone content of assembled chromatin purified by sucrose gradient centrifugation. Histone $\mathrm{H} 1$ cosedimented with the reconstituted chromatin when the assembly was carried out with doublestranded plasmid DNA (Fig. 5A, lane 4) or single-stranded DNA (lane 3), but not in the absence of DNA (lane 5). Furthermore, when chromatin reconstituted in the presence of $\mathrm{H} 1$ was analyzed by micrococcal nuclease digestion, an increased nucleosome repeat length was observed (Fig. 5B). A densitometer tracing (Fig. 5C, upper panel) showed that the nucleosome repeat length was increased from $180 \mathrm{bp}$ in the absence of $\mathrm{H} 1$ to $\sim 197$ bp when $\mathrm{H} 1$ was present; this length is essentially identical to the in vivo repeat length for postblastoderm chromatin (Fig. 5C, lower panel).

Transcriptional repression of DNA templates assembled in chromatin. In order to assess the transcriptional potential of chromatin templates assembled in vitro, two DNA templates carrying the $h s p 70$ and fushi tarazu gene promoters were assembled in the presence or absence of exogenous histone $\mathrm{H} 1$ and assayed by in vitro transcription. A naked, $h s p 70$ minigene template was also introduced into the transcription mixture as a free DNA control. As shown in Fig. 6, increasing nucleosome assembly resulted in the progressive repression of transcription from both $h s p 70$ and fushi tarazu templates. By 60 min of chromatin assembly, when the DNA templates were assembled in a regular nucleosomal array as gauged by the appearance of a defined ladder of DNA fragments after micrococcal nuclease digestion (data not 

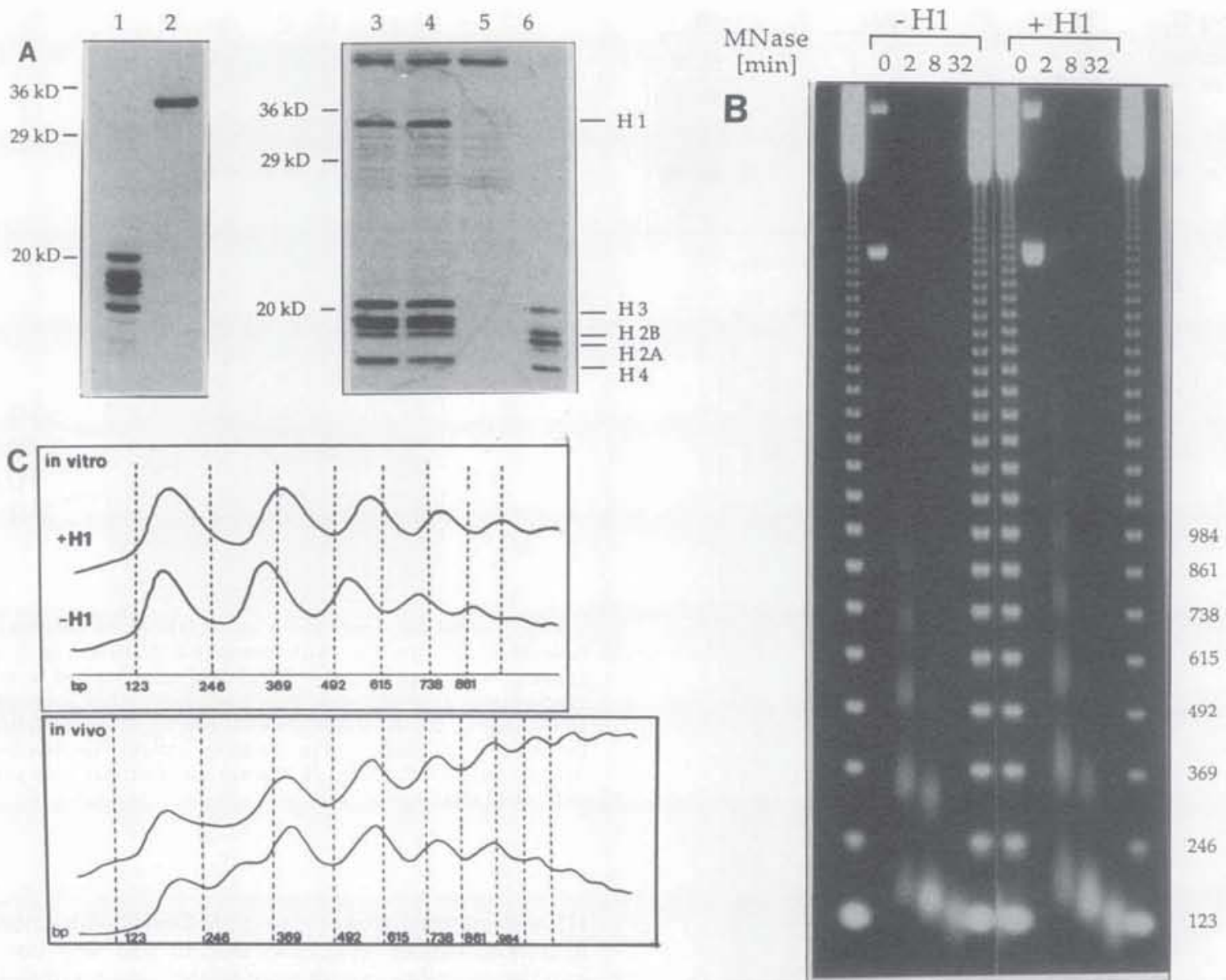

FIG. 5. Incorporation of exogenous histone $\mathrm{Hl}$ into assembled chromatin. (A) Chromatin assembly reactions ( $400 \mu \mathrm{l})$ that contained either single-stranded DNA (lane 3), double-stranded DNA (lane 4), or no DNA (lane 5) and $15 \mu \mathrm{l}$ of H1 were fractionated by sucrose gradient centrifugation. Proteins that cosedimented with the assembled minichromosomes (or the equivalent fractions in the reaction lacking DNA) were pelleted through a sucrose cushion, analyzed by SDS-PAGE, and silver stained. Lanes 1 and 6 , core histones purified from the chromatin of 0 - to 20-h embryos; lane 2, histone $\mathrm{H1}(5 \mu \mathrm{l})$. The staining of the histone $\mathrm{H} 2 \mathrm{~A}$ band in lanes 3 and 4 is low, compared with that of the histone H2B band. (B) Micrococcal nuclease analysis of $1.5 \mu \mathrm{g}$ of plasmid DNA, assembled as described in the Fig. $2 \mathrm{~A}$ legend for $6 \mathrm{~h}$ in the absence or presence of $12 \mu \mathrm{l}$ of H1. Size markers are as in Fig. 2A. (C) Upper panel: densitometer tracing of the lanes displaying the 2-min digestion products of panel $\mathrm{B}$. The tracings were aligned with respect to the neighboring marker lanes to illustrate the change in repeat length. Lower panel: nuclei isolated from 6- to 18-h embryos were digested with micrococcal nuclease, and the digestion products were analyzed on a $1.3 \%$ agarose gel. Densitometer tracings of two lanes showing different extents of digestion are provided.

shown), essentially total repression was observed whether or not histone $\mathrm{H} 1$ was incorporated into the chromatin template (Fig. 6A, lanes 5 and 11). Maximal repression was obserted even in the absence of full nucleosome assembly (which is accomplished in $6 \mathrm{~h}$ ). As in previous studies, these findings indicate that a high, but not necessarily maximal, density of regularly spaced nucleosome core particles is sufficient to repress transcription in vitro. At early time points of the assembly reaction $(5,10$, and $20 \mathrm{~min})$, when nucleosome assembly is suboptimal, there was a modes increase in the level of repression that was dependent on exogenous histone H1 (Fig. 6A; compare lanes 2 to 4 with lanes 8 to 10) (see Fig. 6B for quantitation). This requirement for histone $\mathrm{H} 1$ in transcriptional repression when nucleosomes are assembled in vitro at low density is very similar to what was previously reported concerning the effect of histone $\mathrm{H} 1$ on transcription by Xenopus RNA polymerase III $(34,35)$.

\section{DISCUSSION}

We have characterized an in vitro nucleosome assembly extract from preblastoderm Drosophila embryos. Early Drosophila embryos replicate their genomes on average once every $9 \mathrm{~min}(11)$ and assemble the newly synthesized DNA into chromatin by using the maternal pool of histones and assembly factors. They are thus an excellent source of the components required for replication and chromatin assembly. The extraction procedure we have employed was adapted from recent studies of in vitro chromatin assembly that used Xenopus oocytes as the starting material $(34,35)$. The Drosophila assembly system is characterized by a number of features that render it a highly useful alternative for studies on chromatin assembly. (i) Microgram amounts of plasmid DNA can be quantitatively assembled into chromatin carrying the maximal number of regularly spaced nucleosomes. (ii) The nucleosomes assembled in vitro re- 


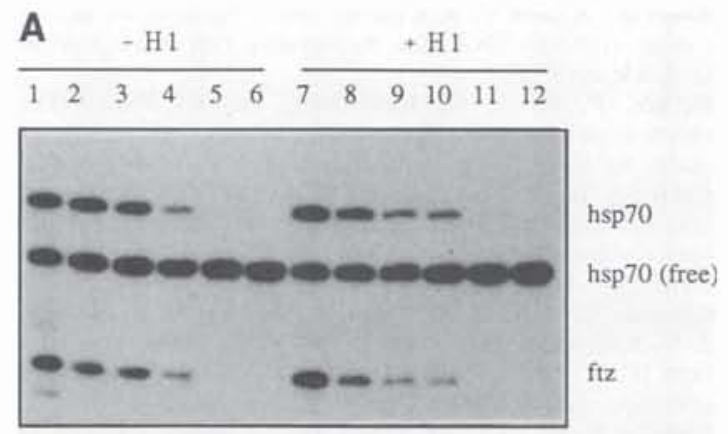

B
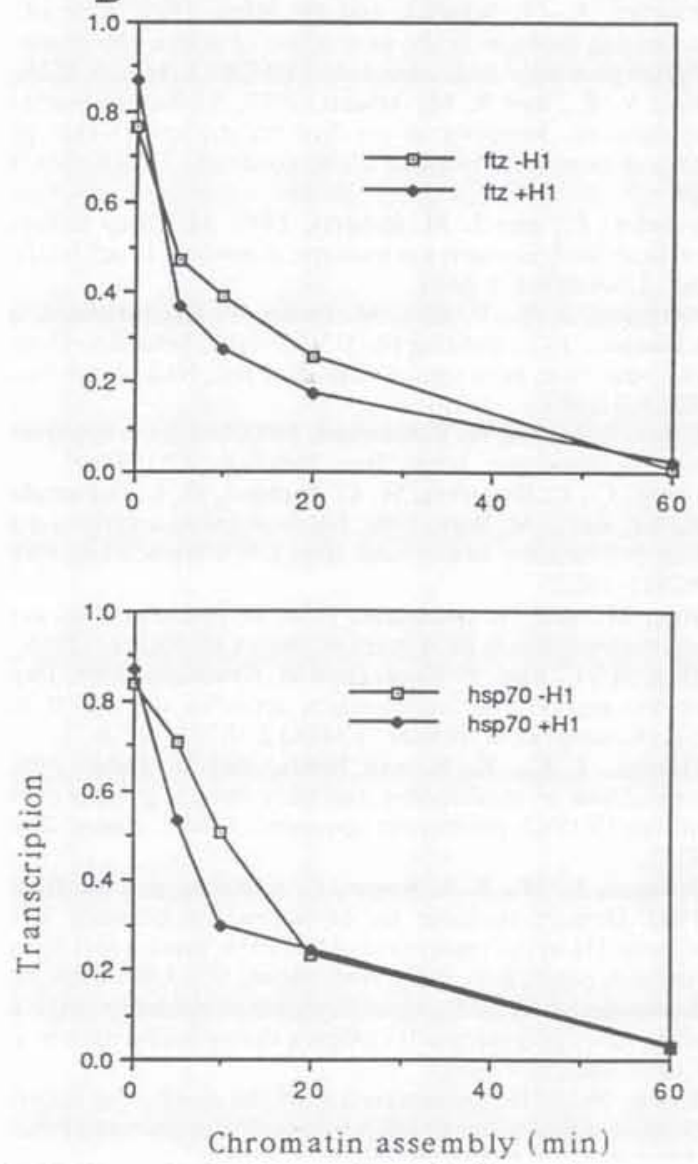

FIG. 6. Transcriptional repression of DNA templates assembled in chromatin. (A) Plasmids containing the $h s p 70$ and fushi tarazu $(f t z)$ promoters were assembled for $0,5,10,20$, and 60 min (lanes 1 to 5 and 7 to 11 ) in the absence or presence of histone $\mathrm{Hl}$, as indicated. After quenching the assembly reaction with excess carrier DNA, an $h s p 70$ minigene was introduced as free DNA and the mixture was incubated in an in vitro transcription extract. The RNA products derived from each template are displayed by primer extension (6). The transcription reactions in lanes 6 and 12 lacked plasmid chromatin templates and served as controls for subtracting background radioactivity for signals derived from the chromatin templates. (B) Graphical representation of the level of transcription of the chromatin templates relative to transcription of the free template. semble native core particles with regard to the stoichiometry of core histone content and the spacing of the nucleosomes on the DNA. (iii) As in the Xenopus system (1-4), the Drosophila extract can be used either to assemble nucleosomes onto double-stranded plasmid DNA or in conjunction with DNA synthesis starting from a single-stranded template. Chromatin that does or does not contain histone $\mathrm{H} 1$ can be obtained. (iv) Large quantities of extracts with high activities are easily and reproducibly prepared according to the standard protocol. In particular, we have not encountered the seasonal variation in the activity of extracts prepared from frog oocytes. The extracts can be kept for many months at $-80^{\circ} \mathrm{C}$ and can be thawed and frozen several times without noticeable loss of activity.

There are several technical points important to the overall activity of the assembly extract that should be noted. The Drosophila embryos are homogenized in a low volume of extraction buffer in order to minimize the dilution of cytoplasmatic assembly components and, presumably, to approach physiological assembly conditions. The extract buffer contains low salt, $10 \mathrm{mM} \mathrm{KCl}$, which minimizes extraction of nuclear proteins into the cytosol. The extended centrifugation at $150,000 \times g$ in the presence of $5 \mathrm{mM}$ magnesium pellets ribosome subunits from the extract that would otherwise obscure the analysis of plasmid chromatin proteins (35). The low ionic strength of the extraction buffer also enables the assembly reaction to be carried out in the presence of an energy regenerating system (ATP and creatine phosphate) and $7 \mathrm{mM} \mathrm{MgCl}$, which are necessary for the assembly of long arrays of spaced nucleosomes. Importantly, the assembly relies entirely on the endogenous pool of maternal histones and their carrier proteins and assembly factors, the native state and stoichiometry of which is maintained. This may be crucial for the reconstitution of long arrays of spaced nucleosomes on natural DNA sequences, a property lacking in chromatin reconstituted by using polyanions as an assembly vehicle for exogenous histones (e.g., see references 26,33 , and 41 and references therein).

The pool of components required for proper nucleosome assembly should be highest in the early embryos and should be rapidly depleted as replication proceeds. Indeed, older Drosophila embryos (4 to $6 \mathrm{~h}$ after egg laying) yielded significantly weaker extracts (data not shown). Extracts from Xenopus oocytes, which also contain a maternal histone pool, are similarly efficient in quantitatively assembling large amounts of plasmid DNA into chromatin while maintaining a high degree of regular nucleosomal spacing $(34,35)$. Tissue culture cells may not be as rich in assembly components, which suggests why cell-free chromatin assembly systems derived from mammalian cells appear to be less potent $(5,15)$.

In agreement with previous reports $(2,5,30)$, elevated concentrations of $\mathrm{MgCl}_{2}$ are required to reconstitute extensive arrays of spaced nucleosomes in our cell-free system (Fig. 2). Interestingly, we have observed rapid supercoiling of plasmid DNA in the extract at protein concentrations insufficient for the generation of spaced nucleosomes and at a suboptimal $\mathrm{MgCl}_{2}$ concentration (1.5 mM; data not shown). Whether this supercoiling is a result of the winding of the DNA around subnucleosomal particles, such as H3-H4 tetramers, remains to be established. Such particles are likely to be intermediates in the assembly of nucleosome cores $(1,12,18,26,32,39)$.

The lack of histone $\mathrm{Hl}$ in chromatin reconstituted by the early embryo extract is not due to a deficiency of the 
assembly machinery, since exogenous $\mathrm{H} 1$ can be efficiently assembled, resulting in an increased linker length. The nucleosomal spacing of chromatin assembled in the presence of exogenous $\mathrm{H} 1$ is very similar to the natural spacing of bulk chromatin in postblastoderm embryos. Hence, chromatin assembled with exogenous histone $\mathrm{Hl}$ in vitro closely approximates the physiological structure. Although $\mathrm{H} 1$ assembly is a determinant of the average linker length between core particles, it appears not to be required for regular spacing of nucleosomes on the DNA itself. Such a function may be dependent on other factors present in the extract, analogous to those found in the Xenopus system and mammalian systems $(32,38)$. It will be of interest to further determine at nucleotide resolution whether the specific positions of nucleosomes assembled in vitro under physiological conditions are exactly equivalent to those found in vivo or to those reconstituted by using other procedures, such as salt dialysis.

A recent study with chromatin templates reconstituted with core histones and histone $\mathrm{H} 1$ has implied a significant role for histone $\mathrm{H} 1$ in the repression of transcription by RNA polymerase II (24). The present results with the $h s p 70$ and fushi tarazu promoters, and previous reconstitution studies with Xenopus oocyte extracts, indicate, however, that the optimal assembly of regularly spaced nucleosome cores is sufficient to maximally repress transcription in vitro, even in the absence of histone $\mathrm{H} 1$. It is probable that the different effects observed with histone $\mathrm{Hl}$ are due to the different procedures employed for core histone deposition, which lead to differences in the spacing of reconstituted nucleosomes. It is also possible that a requirement for repression by histone $\mathrm{Hl}$ is specific to the individual promoter sequences used in the separate studies.

The ability to assemble different types of chromatin under near-replicative conditions in vitro opens avenues for studying the competition between histone deposition during DNA synthesis and the binding of factors that govern transcriptional activation. Moreover, the preblastoderm cytoplasmic extract itself does not support RNA polymerase II transcription (data not shown), in contrast to the nuclear extracts derived from later embryos which are highly active for transcription $(20,40)$. An extract for nucleosome reconstitution that is free of interfering transcription initiation by polymerase II should be a particularly useful alternative to the assembly systems derived from Xenopus eggs and oocytes for studies on the interrelationships between transcriptional regulators and chromatin structure $(6,7,22,47$, 48).

\section{ACKNOWLEDGMENTS}

We thank A. Wolffe for helpful suggestions and G. Wall for excellent technical assistance with the transcription experiments. We also thank two referees for helpful comments.

P.B.B. was supported by a fellowship from the Fogarty International Center.

\section{REFERENCES}

1. Almouzni, G., D. J. Clark, M. Méchali, and A. P. Wolffe. 1990. Chromatin assembly on replicating DNA in vitro. Nucleic Acids Res. 18:5767-5774.

2. Almouzni, G., and M. Méchali. 1988. Assembly of spaced chromatin promoted by DNA synthesis in extracts from Xenopus eggs. EMBO J. 7:665-672.

3. Almouzni, G., and M. Méchali. 1988. Assembly of spaced chromatin: involvement of ATP and DNA topoisomerase activity. EMBO J. 7:4355-4365.

4. Almouzni, G., M. Méchali, and A. P. Wolffe. 1990. Competition between transcription complex assembly and chromatin assembly on replicating DNA. EMBO J. 9:573-582.

5. Banerjee, S., and C. R. Cantor. 1990 . Nucleosome assembly of simian virus 40 DNA in a mammalian cell extract. Mol. Cell. Biol. 10:2863-2873.

6. Becker, P. B., S. K. Rabindran, and C. Wu. 1991. Heat shock-regulated transcription in vitro from a reconstituted chromatin template. Proc. Natl. Acad. Sci. USA 88:4109-4113.

7. Corthésy, B., P. Léonard, and W. Wahli. 1990. Transcriptional potentiation of the vitellogenin B1 promoter by a combination of both nucleosome assembly and transcription factors: an in vitro dissection. Mol. Cell. Biol. 10:3926-3933.

8. Croston, G. E., L. E. Kerrigan, L. M. Lira, D. R. Marshak, and J. T. Kadonaga. 1991. Sequence-specific antirepression of histone H1-mediated inhibition of basal RNA polymerase II transcription. Science 251:643-649.

9. Elgin, S. C. R., and L. E. Hood. 1973. Chromosomal proteins of Drosophila embryos. J. Biol Chem. 12:4984-4991.

10. Fascher, K., J. Schmitz, and W. Hörz. 1990. Role of transactivating proteins in the generation of active chromatin at the PHO5 promoter in S. cerevisiae. EMBO J. 9:2523-2528.

11. Foe, V. E., and B. M. Alberts. 1983. Studies of nuclear and cytoplasmic behavior in the five mitotic cycles that precede gastrulation in Drosophila embryogenesis. J. Cell. Sci. 61:3170.

12. Fotedar, R., and J. M. Roberts. 1989. Multistep pathway for replication-dependent nucleosome assembly. Proc. Natl. Acad. Sci. USA 86:6459-6463.

13. Germond, J. E., P. Hirt, M. Oudet, P. Gross-Bellard, and P. Chambon. 1975. Folding the DNA double helix into chromatinlike structures from simian virus 40. Proc. Natl. Acad. Sci. USA 72:1843-1847.

14. Gross, D. S., and W. T. Garrard. 1990. Nuclease hypersensitive sites in chromatin. Annu. Rev. Biochem. 57:159-197.

15. Gruss, C., C. Gutierrez, W. C. Burhans, M. L. DePamphilis, T. Koller, and J. M. Sogo. 1990. Nucleosome assembly in mammalian cell extracts before and after DNA replication. EMBO J. 9:2911-2922.

16. Han, M., and M. Grunstein. 1988. Nucleosome loss activates yeast downstream promoters in vivo. Cell 55:1137-1145.

17. Han, M., U. Kim, P. Kayne, and M. Grunstein. 1988. Depletion of histone $\mathrm{H} 4$ and nucleosomes activates the PHOS gene in Saccharomyces cerevisiae. EMBO J. 7:2221-2228.

18. Hansen, J. C., K. E. van Holde, and D. Lohr. 1991. The mechanism of nucleosome assembly onto oligomers of the sea urchin 5S DNA positioning sequence. J. Biol. Chem. 266:42764282.

19. Johnson, L. M., P. S. Kayne, E. S. Kahn, and M. Grunstein. 1990. Genetic evidence for an interaction between SIR3 and histone $\mathrm{H} 4$ in the repression of the silent mating loci in Saccharomyces cerevisiae. Proc. Natl. Acad. Sci. USA 87:6286-6290.

20. Kadonaga, J. T. 1990 . Assembly and disassembly of the Drosophila RNA polymerase II complex during transcription. J. Biol. Chem. 265:2624-2631.

21. Keller, W. 1975. Determination of the number of superhelical turns in simian virus 40 DNA by gel electrophoresis. Proc. Natl. Acad. Sci. USA 72:4876-4880.

22. Laskey, R. A., and W. C. Earnshaw. 1980. Nucleosome assembly. Nature (London) 286:763-767.

23. Laskey, R. A., A. D. Mills, and N. N. Morris. 1977. Assembly of SV 40 chromatin in a cell-free system from Xenopus eggs. Cell 10:237-243.

24. Laybourn, P. J., and J. T. Kadonaga. 1991. Role of nucleosomal cores and histone $\mathrm{Hl}$ in regulation of transcription by RNA polymerase II. Science 254:238-245.

25. Nelson, T., T. Hsieh, and D. Brutlag. 1979. Extracts of Drosophila embryos mediate chromatin assembly in vitro. Proc. Natl. Acad. Sci. USA 76:5510-5514.

26. Nelson, T., R. Wiegand, and D. Brutlag. 1981. Ribonucleic acid and other polyanions facilitate chromatin assembly in vitro. Biochemistry 20:2595-2601.

27. Noll, M., and R. D. Kornberg. 1977. Action of micrococcal nuclease on chromatin and the location of histone H1. J. Mol. 
Biol. 109:393-404.

28. Pederson, D. S., and R. T. Simpson. 1988. Structural and regulatory hierarchies in transcriptionally active chromatin. ISI Atlas Sci. Biochem. 1:155-160.

29. Pulleyblank, D. E., M. Shure, D. Tang, J. Vinograd, and H. P. Vosberg. 1975. Action of nicking-closing enzyme on supercoiled and nonsupercoiled closed circular DNA: formation of Boltzman distribution of topological isomers. Proc. Natl. Acad. Sci. USA 72:4280-4284.

30. Rodriguez-Campos, A., A. Shimamura, and A. Worcel. 1989. Assembly and properties of chromatin containing histone H1. J. Mol. Biol. 209:135-150.

31. Roth, S. Y., A. Dean, and R. T. Simpson. 1990. Yeast $\alpha 2$ repressor positions nucleosomes in TRP1/ARS1 chromatin. Mol. Cell. Biol. 10:2247-2260.

32. Sapp, M., and A. Worcel. 1990. Purification and mechanism of action of a nucleosome assembly factor from Xenopus oocytes. J. Biol. Chem. 265:9357-9365.

33. Sealy, L., R. R. Burgess, M. M. Cotten, and R. Chalkey. 1989. Purification of Xenopus egg nucleoplasmin and its use in chromatin assembly in vitro. Methods Enzymol. 170:612-630.

34. Shimamura, A., M. Sapp, A. Rodriguez-Campos, and A. Worcel. 1989. Histone $\mathrm{Hl}$ represses transcription from minichromosomes assembled in vitro. Mol. Cell. Biol. 9:5573-5584.

35. Shimamura, A., D. Tremethick, and A. Worcel. 1988. Characterization of the repressed 5S DNA minichromosomes assembled in vitro with a high-speed supernatant of Xenopus laevis oocytes. Mol. Cell. Biol. 8:4257-4269.

36. Simon, R. H., and G. Felsenfeld. 1979. A new procedure for purifying histone pairs $\mathrm{H} 2 \mathrm{~A}+\mathrm{H} 2 \mathrm{~B}$ and $\mathrm{H}_{3}+\mathrm{H}_{4}$ from chromatin using hydroxylapatite. Nucleic Acids Res. 6:689-696.

37. Simpson, R. T. 1991. Nucleosome positioning: occurrence, mechanisms, and functional consequences. Prog. Nucleic Acid Res. Mol. Biol. 40:143-183.

38. Smith, S., and B. Stillman. 1989. Purification and characterization of CAF-1, a human cell factor required for chromatin assembly during DNA replication in vitro. Cell 58:15-25.
39. Smith, S., and B. Stillman. 1991. Stepwise assembly of chromatin during DNA replication in vitro. EMBO J. 10:971-980.

40. Soeller, W. C., S. J. Poole, and T. Kornberg. 1988. In vitro transcription of the Drosophila engrailed gene. Genes Dev. 2:68-81.

41. Stein, A. 1989. Reconstitution of chromatin from purified components. Methods Enzymol. 170:585-603.

42. Straka, C., and W. Hörz. 1991. A functional role for nucleosomes in the repression of a yeast promoter. EMBO J. 10:361368.

43. Svaren, J., and R. Chalkey. 1990. The structure and assembly of active chromatin. Trends Genet. 6:52-55.

44. von Holt, C., W. F. Brandt, H. J. Greyling, G. G. Lindsey, J. D. Retief, J. D. A. Rodrigues, S. Schwager, and B. T. Sewell. Isolation and characterization of histones. Methods Enzymol. 170:431-523.

45. Wolffe, A.P. 1990 . New approaches to chromatin function. New Biol. 2:211-218.

46. Wolffe, A. P. 1989. Dominant and specific repression of Xenopus oocyte 5S RNA genes and satellite I DNA by histone H1 EMBO J. 8:527-537.

47. Workman, J. L., R. G. Roeder, and R. E. Kingston. 1990. An upstream transcription factor, USF (MLTF), facilitates the formation of pre-initiation complexes during in vitro chromatin assembly. EMBO J. 9:1299-1308.

48. Workman, J. L., I. C. A. Taylor, and R. E. Kingston. 1991 Activation domains of stably bound GAL4 derivatives alleviate repression of promoters by nucleosomes. Cell 64:533-544.

49. Wray, W., T. Boulikas, V. P. Wray, and R. Hancock. 1981 Silver staining of proteins in polyacrylamide gels. Anal. Biochem. 118:197-203.

50. Wu, C., P. M. Bingham, K. J. Livak, R. Hoimgren, and S. R. C. Elgin. 1979. The chromatin structure of specific genes. I. Evidence for higher order domains of defined DNA sequence. Cell 16:797-806.

51. Zlatanova, J. 1990. Histone $\mathrm{H} 1$ and the regulation of transcription of eukaryotic genes. Trends Biochem. Sci. 15:273-276. 